\title{
Extraversion and Female EFL Learners as Listeners: A Qualitative Investigation
}

\author{
Ahmet Selçuk Akdemir ${ }^{1, *}$, Mehmet Takkaç² \\ ${ }^{1}$ Faculty of Science and Letters, Agri Ibrahim Cecen University, Turkey \\ ${ }^{2}$ Faculty of Education, Ataturk University, Turkey
}

Copyright $\bigcirc 2016$ by authors, all rights reserved. Authors agree that this article remains permanently open access under the terms of the Creative Commons Attribution License 4.0 international License.

\begin{abstract}
This study aims to investigate extraversion as a personality trait of female EFL learners as listeners. The study is based on qualitative research design. Five students, who were studying as freshman students at English Language Teaching Department of a public university in Turkey, are the participants of the study. All participants have been selected among freshman students of the department. Data which was collected with semi-structured interviews was transcribed verbatim by the researcher himself and then it was analysed with content analysis method. According to results of the study, extraversion is found to be a significant personality trait of female EFL learners as listeners. Besides, six sub-dimensions of extraversion were identified under two main categories. The study is expected to contribute the literature in terms of a detailed investigation of extraversion for female EFL learners as listeners.
\end{abstract}

Keywords EFL Listening, Female Language Learners, Extraversion, Big Five Factors

\section{Introduction}

Extraversion, one of the Big five factors (BFF), has recently been a topic of interest for the research on the personality traits of language learners. Several studies have investigated whether extraversion impacts language learning process and proficiency level of learners (see following chapter for an extensive review of literature). Yet, these studies fail in exploring the concept in depth. The literature is full of studies trying to correlate extraversion with language learning or proficiency. Extraversion has not been investigated regarding its reflections in female EFL learners as listeners. This study, which is part of a larger qualitative investigation, aims at exploring extraversion as a personality trait of female EFL learners as listeners. To that aim, the content of a qualitative inquiry has been collected and analyzed. The results have been discussed in the light of the literature.

\section{Theoretical Framework}

\subsection{Big Five Factors}

BFF, five dimensions of personality, are also known as the 'Five Factor Model (FFM)' [1]. Relevant studies have started with Cattel's works in 1940's. Cattel, cited in [2], created the initial taxonomy of personality traits. Later on, his taxonomy was developed by many scholars [1-10]. These factors are generally listed as:

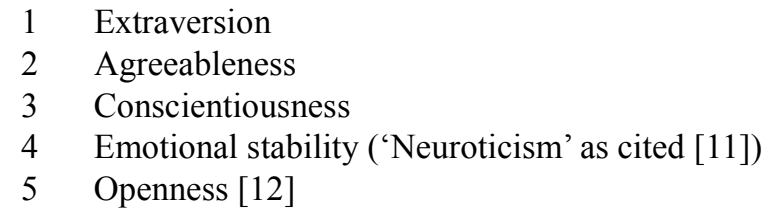

It was Goldberg [13] who named these factors the 'Big Five' "not to reflect their intrinsic greatness but to emphasize that each of these factors is extremely broad" [2]. Over time, these factors found their way into language studies. They were defined as the factors affecting the language learning process [11]. Being an extravert or introvert is found to be an important variable on deciding a learner's learning style and success.

\subsection{Extraversion in L2 Listening}

A number of studies have examined the impact of extraversion on language learning [14-18]. As a personality factor and one of the BFF, extraversion is suggested to affect learner's learning styles and proficiency in a positive way as it is associated with sociability, assertiveness and enthusiasm [19]. According to research, extraverted language learners achieve greater fluency in oral production tasks. They are also found to be more successful in terms of communicative aspects of language [20-25]. Also, there are few studies which have found little or no positive 
correlation between extraversion and language proficiency [26-28]. These studies are mostly based on one-dimensional assessment of language proficiency.

\subsection{The Effect of Gender: Females' Part}

Literature on the impact of gender in extraversion as a personality factor is relatively restricted. Few studies have focused on female language learners in terms of extraversion. Thorne [29] examined extraversion on female language learners' conversation styles. She compared statistical results obtained from extraverted and introverted learner groups and the results revealed that extravert learners are more successful in certain communicative tasks. Robson [30] found that female extraverted students are more active in oral tasks of English classes. According to Wakamoto [31], who studied the relationship between extraversion-introversion and language learning strategies of female students, there exists a significant correlation between extraversion and certain language learning strategies which he described as 'functional practice strategies' and 'social affective strategies'. The correlation between language learning strategies and extraversion has been investigated in a qualitative research by Fazeli [32]. $\mathrm{He}$ found a significant relationship between extraversion and three of the six categories of language learning strategies, which are namely memory, metacognitive and social strategies.

As part of a larger qualitative research, this study aims at investigating extraversion and its sub-dimensions with various themes in terms of female EFL learners as listeners. The study is expected to contribute the literature as well as enabling a better conceptualizing of the relationship between gender and extraversion.

\section{Method}

\subsection{Instrumentation}

In this study, a semi-structured interview was used as the main data collection instrument. In this type of interview, according to Mackey and Gass [33] 'the researcher uses a written list of questions as a guide, while still having the freedom to digress and probe for more information'. Kvale [34] states that interviews are 'the attempts to understand the world from the subjects' point of view, to unfold the meaning of peoples' experiences, to uncover their lived world prior to scientific explanations'. Creswell [35] suggests interviews as useful instruments when the participants cannot be directly observed. Rich data about peoples' experiences, perceptions, opinions, feelings and knowledge can be derived through interviews [36-39]. According to Kvale [34], there are two contrasting metaphors of the interviewer: interviewer as a miner or as a traveller in both of which the aim of the researcher is to explore or uncover the knowledge.
The participants were interviewed by the researcher himself in their department. They were all informed about the whole process of the study. An informed consent form (See Appendix 1) was used to ensure ethical research. They were told of the voluntary manner of participation, and that there were no expected - psychological, physical and/or professional - risks or harms, approximate duration, and finally of the confidentiality of the data. An interview protocol (See Appendix 2) was constructed for the semi-structured interviews which aimed at exploring the characteristics of language learners as listeners. The interview protocol consisted of an introduction of the research topic, basic demographic and introductory questions to serve as a warm up section, main questions and thanking the participant for taking part in the study. The interviews were conducted in Turkish as the participants preferred it to feel more comfortable. Before the main interviews, two preliminary pilot studies were conducted to check and revise internal (research questions, duration, comfort/discomfort of the participant etc.) and external (audio-recorder, outer disturbance, noise etc.) factors that could affect the interview adversely. According to the data and observations of pilot studies, some internal and external factors were revised. The main interviews were conducted in an office of the participants' department. The average duration for the interviews was 32 minutes, the shortest one being 22 minutes and the longest one being 47 minutes. Subsequently, all the interviews were transcribed verbatim by the researcher and they were all checked by two anonymous researchers in terms of consistency with the audio recordings. The excerpts taken from the responses of the interviewees were translated by the researcher and they were checked by two colleagues for their consistency with the transcriptions. This paper reports on a part of a larger study. In the original research, which was submitted as a doctoral dissertation, the characteristics of language learners as listeners were investigated through a qualitative investigation. This paper is focused on extraversion and female EFL learners as listeners.

\subsection{Procedures and Participants}

After collecting and transcribing the data, an analysis process was conducted with Creswell's [40] approach as guide to the researcher. The transcriptions were read by the research as many times as necessary and codes were formed. According to Creswell [41], coding is 'the process of segmenting and labelling text to form descriptions and broad themes in the data' (p. 243). After forming the codes, they were combined into categories and these categories were linked with the themes, selected in accordance with existing literature. BFF were selected as pre-determined themes of the study. Extraversion, one of the BFF, was investigated in terms of female EFL learners as listeners. As the codes were formed, themes and categories were revised for their consistency. The outcome of data analysis has led the researcher to find answers to research questions and to 
have an in-depth understanding of the phenomenon under discussion.

As important components of qualitative studies, participants should be selected carefully to conform to the research questions as well as the aim of the study. The participants of this study were selected among the classes of the department where listening skill is taught and practiced during preparatory and first years under different courses. Students have 'Listening' course 5 hours per week during preparatory class. In the first year there is 'Listening and Pronunciation' course (105 AL/106 AL) which is carried out 3 hours per week. Data was collected at the end of academic year (2011-2012 Spring) which means all the participants, as first year students, had two years of listening courses. None of the participants were reported to have any listening education prior to their university life.

After recruiting the participants, they were informed about the study and a meeting date was set suitable for both parties (the researcher and the participants). Those whose consents were taken were chosen as the participants. Biographical information of the participants is provided in the table below (Table 1). The participants were asked to choose pseudonyms to ensure confidentiality of the study.

Table 1. Biographical Information of the Participants*

\begin{tabular}{|c|c|c|c|}
\hline $\begin{array}{c}\text { Pseudonyms } \\
\text { For The } \\
\text { Participants }\end{array}$ & DEPARTMENT & AGE & GENDER \\
\hline Burcu & ELT & 19 & Female \\
\hline Elif & ELT & 20 & Female \\
\hline Melek & ELT & 24 & Female \\
\hline Nur & ELT & 18 & Female \\
\hline Su & ELT & 19 & Female \\
\hline
\end{tabular}

*The names are in alphabetical order.

\section{Results and Discussion}

Participants of this study reported two main categories of extraversion: sociability and enthusiasm (Table 2) which revealed six unique characteristics of listeners:
a. Being open-minded
b. Being empathic
c. Making eye contact
d. Context-bound willingness
e. Content-bound willingness
f. Mood dependent willingness

Table 2. Extraversion

\begin{tabular}{|c|c|}
\hline \multicolumn{2}{|c|}{ THEME: EXTRAVERSION } \\
\hline CATEGORIES & CODES \\
\hline Category 1: Sociability & $\begin{array}{c}\text { Open-minded } \\
\text { Empathic } \\
\text { (making) Eye contact }\end{array}$ \\
\hline Category 2: Enthusiasm & $\begin{array}{c}\text { (context-bound) willing } \\
\text { (content-bound) willing } \\
\text { (mood dependent) willing }\end{array}$ \\
\hline
\end{tabular}

It is notable that all of the participants reported at least one of the characteristics inferable from extraversion. Being 'open-minded' was emphasized to refer that the participant is open to new ideas as well as newly presented information. As the participants stated, newly presented information is acceptable even it contrasts with their existing knowledge:

'I listen whatever the speaker tells. Because maybe I will learn new thing from her/his words. Even if they are too different for me, I do not stop listening or leave the topic. I try to relate it with my existing knowledge.' (Su)

'There occurred many cases when I listened and changed my existing beliefs or knowledge. I think a learner should be open to everything. Otherwise how can we learn? While listening in English I change my pronunciation and sometimes I learn new words that are more suitable than my vocabulary. I adopt them.' (Nur)

As an emotional and cognitive term, empathy was reported by the participants several times. Those who defined themselves as 'empathic' related the term to the necessities of classroom atmosphere:

'In the classroom I try to empathize with the other. While listening, I do not confine myself to my own ideas or feelings or understanding.' (Elif)

'According to me, the listener should empathize with the speaker, so that s/he can understand all the message the speaker wants to give. I do this during listening in listening classes.' (Nur)

Making eye contact during listening was reported by most of the participants. Like 'respect', 'eye contact' is also typical to cultural context [42]. Several studies emphasize that as a paralinguistic feature of communication, eye contact is an important tool for listening comprehension enabling listener understand the message better $[42,43,44]$. Some participants identified it with 'caring the speaker' or 'giving feedback'; some others revealed cultural and traditional stereotypes as underlying reasons for making eye contact:

'Our listening and pronunciation courses depend on classroom interactions. Sometimes we listen from a $C D$ player and sometimes our teacher talks. When I listen to my teacher or my classmates I rarely lose eye contact because I feel not caring the speaker when my eyes wander.' (Su)

'... and eye contact is crucial for me to comprehend what I am listening to... Yes, eyes are important to indicate it (comprehension). '(Burcu)

'Sometimes I miss the point. For example while listening to my teacher, when I face with a word or phrase that I have never heard before, I miss the point. Our teacher understands it from my eyes. I should give this message to my teacher through eye contact.' (Melek) 
There is much research on 'task difficulty' as a factor determining comprehension of second language listener [45-47]. Task difficulty should be assessed as a content-bound factor affecting listening comprehension. However it is obvious that there are other factors as well. The participants reported 'willingness' with three sub-variables: context-bound, content-bound and mood dependent willingness to listen.

Context-bound willingness was reported as follows:

'While watching a film or listening to a foreigner (a tourist), I mean, out of the classroom, I feel more willing to listen to. I study at home before coming to class and I get bored when listening to the same thing over and over. You have to understand the topic. There are orders you should follow: listen, answer ... It is not enjoyable listening for the lesson. I do not get bored while watching a film in English.' (Burcu)

Content-bound willingness was reported as follow:

'Generally, I get bored easily if the topic is not interesting. For example we have a coursebook for listening and pronunciation class. It has many interesting topics but some others are rather dull and boring. In fact I do not want to even attend to class on those days. Our teacher tries hard to make the lesson interesting but if the topic is dull we get bored easily.' (Su)

I am more interested into it if the topic is one of my favorites.'(Melek)

Mood dependent willingness was reported by one of the participants as follows:

'It depends on my mood. If I do not feel good while listening to English whether it is classroom or at home, it affects my enthusiasm.' (Burcu)

The characteristics revealed in this theme are more likely to be correlated to personality factors. Personality factors are suggested to have a key role 'on the development of L2 basic interpersonal skills' [48]. Liyanage [49] pointed the impact of a learner's cultural background on her/his communication behaviour. Willingness and motivation have been listed as two of personality factors $[23,48]$. Willingness of our participants to listening is found to have been determined by three factors which can be concluded as being sources of motivation. Lightbown and Spada [50] mentioned 'willingness' as one of the characteristics of good language learner.

In their pioneering study on the characteristics of listeners, Steil, Barker and Watson [51] mentioned 'being open minded, making eye contact' and 'willingness' as good characteristics of language learners. However their study lacked a detailed categorization of 'willingness'. Purdy and Newman [52] listed 'willingness' under the name of 'caring attitude' however it is obvious that 'caring' differs from willingness in that the former is related to 'kindness' while the latter is content-bound or context-bound which suggests 'motivation'. Besides, willingness has psychological and cognitive backgrounds which mean 'willingness' is much more complex than it was estimated by previous studies. It is more than 'making listening classes attractive' or 'choosing listening material to attract the learners'.

The participant's answers to interview questions gave hints of psychological and cognitive factors affecting their listening behaviour. It is obvious that their readiness and willingness change depending on internal and external factors. Listening types, material or topic, and the setting have influence on whether a listener is open to comprehend or not.

Being sociable should be considered in terms of personality factors which cause a listener to be good at interpersonal relationships. For example, a listener who feels isolated from her social context may not find it easy to make eye contact while listening in a foreign language.

According to the findings of the study, extraversion is an outstanding characteristic of female EFL learners in terms of listener profile. This qualitative inquiry reflects several dimensions of extraversion. Being open-minded, being empathic, making eye contact and willingness (context-bound, content-bound and mood dependent) are the sub-dimensions of extraversion in EFL listening for female learners. It is important to note that the unique findings of the study are the listener characteristics which have not been identified or investigated in the relevant literature before.

\section{Conclusions}

This study, part of a larger qualitative investigation, aims at investigating extraversion as a personality trait for female EFL learners as listeners. The findings of current study show that extraversion is one of the significant characteristics of female EFL learners. Content analysis of interviews has revealed sub-dimensions of extraversion. These dimensions are notable for any further research on the importance of extraversion in language learning as the relevant literature does not go beyond experimental research designs on extraversion. Also, the listener characteristics defined as sub-dimensions of extraversion for female EFL learners are identified or investigated in depth for the first time. There is no research on three types of willingness (context-bound, content-bound and mood dependent) in the relevant literature. Further research might focus on the findings of this study. Being open-minded, being empathic, making eye contact and willingness (context-bound, content-bound and mood dependent), which are the dimensions of extraversion should be investigated in detail. Various research designs will expand the findings of current study.

Research paradigms need to shift from merely seeking the quantitative differences between two variables in gender-based EFL research. Contemporary 
conceptualization of the effect of gender on L2 listening entails qualitative research designs which enable elaborated reflection of whether female EFL learners show unique characteristics.

\section{Appendix 1: Consent Form}

\section{Informed Consent Form}

Title: A Qualitative Investigation of the Characteristics of Language Learners As Listeners According to the Strategies They Use in EFL Listening.

As a participant in this study, I know this study is about the characteristics of language learners as listeners.

I understand that my participation in this study is entirely voluntary.

I understand that I have the full right to withdraw my consent and end my participation in the study at any time.

I understand the procedures in the study and I understand what will be required of me as a participant.

I understand that all my oral responses will be completely anonymous.

I hereby wish to give my consent for participation in this study. I acknowledge that I received a copy of the information consent form.

For further questions, please contact the researcher by telephone or via email.

Participant's Signature

Researcher's Signature

\section{Appendix 2: Interview Protocol}

Part 1- Introduction

Thank you for being voluntary to take part in this interview. I expect that we will talk for approximately 20 minutes about your listening strategies, characteristics as a listener and an overview of your listening experiences in FL. Before we begin, I will review the Informed Consent Form. Please do not hesitate to ask your questions that may you have.

\section{Part 2- Demographic and Background Information}

Please select a pseudonym that has no direct relation to your name. It will be used throughout the study to ensure confidentiality.

Where do you come from?

Your age:

What are your academic and professional goals?

Did you have prep class in this department?

What was the type of high school you graduated from?

Part 3- Interview

1. Do you like listening? Why?

2. Why do you listen in English? In other words, what are your listening aims?

3. How do you cope with the difficulties you face while listening?

4. What do you think about your listening skill?

5. How do you prepare for listening? (What do you do before listening, during listening and after listening?)

6. How do you describe yourself as a listener?

7. What are your good and poor sides as a listener in listening process both in classroom and social settings?

\section{Part 4- Closure}

Thank you for being voluntary to take part in this study. Please feel free to contact me, if you have something to add. I wish you great success.

\section{Acknowledgements}

This paper is based on a doctoral dissertation titled "A Qualitative Investigation of the Characteristics of Language Learners as Listeners According to the Strategies They Use in EFL Listening".

\section{REFERENCES}

[1] P.T.,Jr. Costa \& R. R. McCrae. Revised NEO Personality Inventory (NEO-PI-R) and NEO Five-Factor Inventory (NEO-FFI) manual. Odessa, FL: Psychological Assessment Resources, 1992.

[2] O. P. John \& S. Srivastava. The big five trait taxonomy: History, measurement and theoretical perspectives. In L. Pervin \& O. P. John (Eds.), Handbook of personality: Theory and research (2nd ed., pp. 102-138). New York: Guilford, 1999.

[3] M. Almagor, A. Tellegen, N. G. \& Waller. The big seven model: A cross-cultural replication and further exploration of the basic dimensions of natural language trait descriptors. Journal of Personality and Social Psychology, 69, 300-307, 1995.

[4] V. Benet-Martinez \& N. G. Waller. Further evidence for the cross-cultural generality of the Big Seven Factor model: Indigenous and imported Spanish personality constructs. Journal of Personality, 65, 567-598, 1997.

[5] W. C. Becker. The matching of behavior rating and questionnaire personality factors. Psychological Bulletin, 57, 201-212, 1960 .

[6] R. B. Cattell, H. W. Eber \& M. M. Tatsuoka. Handbook for the sixteen personality factor questionnaire (16PF). Champaign, IL: IPAT, 1970.

[7] J. M. Digman \& N. K. Takemoto-Chock. Factors in the natural language of personality: Reanalysis and comparison of six major studies. Multivariate Behavioral Research, 16, 149-170, 1981.

[8] O. P. John. The "Big Five" factor taxonomy: Dimensions of personality in the natural language and questionnaires. In L. A. 
Pervin (Ed.), Handbook of personality: Theory and research (pp. 66-100) New York: Guilford Press, 1990.

[9] M. Nowakowska. The limitations of the factor-analytic approach to psychology with special application to Cattell's research strategy. Theory and Decision, 4, 109-139, 1973.

[10] E. C. Tupes \& R. C. Christal. Recurrent personality factors based on trait ratings. Technical Report, USAF, Lackland Air Force Base, TX, 1961

[11] W. Fayyaz \& A. Kamal. Personality traits and the metacognitive listening skills of English as a foreign language in Pakistan. Journal of Behavioural Sciences, 21(2), 59-76, 2011.

[12] D. Ames, L. B. Maissen, \& J. Brockner. The role of listening in interpersonal influence. Journal of Research in Personality, 46, 345-349, 2012.

[13] L. R. Goldberg. Language and individual differences: The search for universals in personality lexicons. In L. Wheeler (Ed.), Review of personality and social psychology, (Vol. 2, pp. 141-165). Beverly Hills, CA: Sage, 1981.

[14] J. M. Dewaele \& A. Furnham. Extraversion: The unloved variable in applied linguistic research. Language Learning, 43(3), 509-544, 1999.

[15] M. E. Ehrman, L. L. Betty \& R. L. Oxford. A brief overview of individual differences in second language learning. System, 31, 313-330, 2003.

[16] R. L. Oxford \& N. J. Anderson. A crosscultural view of learning styles. Language Teaching, 28(4), 201-215, 1995.

[17] S. van Daele, A. Housen, M. Pierrard \& L. DeBruyn. The effect of extraversion on oral L2 proficiency. EUROSLA Yearbook, 6, 213-236, 2006.

[18] E. Wong. Extraversion and introversion in second-language acquisition: A literature review. Nihon University School of Dentistry Bulletin, 39, 1-10, 2011.

[19] M. R. Barrick, M. K. Mount. The big five personality dimensions and job performance: A meta-analysis. Personnel Psychology, 44 (1), pp. 1-26, 1991.

[20] V. Berry. Personality differences and oral test performance. Frankfurt: Peter Lang, 2007.

[21] V. Cook. Portraits of the L2 user. Clevedon: Multilingual Matters Ltd, 2002.

[22] J. M. Dewaele \& A. Furnham. Personality and speech production: a pilot study of second language learners. Personality and Individual Differences, 28, pp. 355-365, 2000.

[23] Z. Dörnyei. The psychology of the language learner: Individual differences in second language acquisition. Mahwah, NJ: Lawrence Erlbaum Associates, 2005.

[24] T. Oya, E. Manalo \& J. Greenwood. The influence of personality and anxiety on the oral performance of Japanese speakers of English. Appl. Cognit. Psychol., 18: 841-855. doi: 10.1002/acp.1063, 2004.

[25] H. M. Sidek. EFL language learning personality traits and instruction. The International Journal of Learning, 18, 255-272, 2012.
[26] A. Boroujeni, A. Roohani \& A. Hasanimanesh. The Impact of Extroversion and Introversion Personality Types on EFL Learners' Writing Ability. Theory \& Practice In Language Studies, 5(1), 212-218. doi:10.17507/tpls.0501.29, 2015.

[27] Y. Chen, Y. Jiang \& Z. Mu. A Survey Study: The Correlation between Introversion/Extroversion and Oral English Learning Outcome. Journal of Language Teaching \& Research, 6(3), 581-587, 2015.

[28] R. G. Kiany. English proficiency and academic achievement in relation to extraversion: A preliminary study. International Journal of Applied Linguistics, 8(1), 113-130, 1998.

[29] A. Thorne. The press of personality: A study of conversations between introverts and extraverts. Journal of Personality \& Social Psychology, 53, pp. 718-726, 1987.

[30] G. L. Robson. Relationships between personality, anxiety, proficiency and participation (Doctoral dissertation).Temple University Japan, 1994.

[31] N. Wakamoto. Language learning strategy and personality variables: Focusing on extroversion and introversion. International Review of Applied Linguistics in Language Teaching, 38, 71-81, 2000.

[32] S. H. Fazeli. The relationship between the extraversion trait and use of the English language learning strategies. Indian Journal of Science and Technology, 5(4), 2651-2657, 2012.

[33] A. Mackey \& S. M. Gass. Second language research: Methodology and design. Mahwah, NJ: Lawrence Erlbaum Associates, 2005.

[34] S. Kvale. InterViews: An introduction to qualitative research interviewing. Thousand Oaks, CA, Sage, 1996.

[35] J. W. Creswell. Research design: Qualitative, quantitative and mixed methods approaches (2nd ed.). Thousand Oaks, CA, Sage, 2003.

[36] R. C. Bogdan \& S. K. Biklen. Qualitative research for education: An introduction to theory and methods. Boston, Allyn and Bacon, 1998.

[37] J. A. Maxwell. Qualitative research design: An interactive approach (2nd ed.). Thousand Oaks, CA, Sage, 2005.

[38] M. Q. Patton. Qualitative research \& evaluation methods (3rd. ed.). Thousand Oaks, CA, Sage, 2002.

[39] M. Trumbull. Qualitative research methods. In G. R. Taylor (Ed.), Integrating quantitative and qualitative methods in research (2nd. ed., pp. 101-126), Lanham, University Press of America, 2005.

[40] J. W. Creswell. Qualitative inquiry and research design: Choosing among five traditions. Thousand Oaks, CA, Sage, 1998.

[41] J. W. Creswell. Educational research: Planning, conducting, and evaluating quantitative and qualitative research (4th Edition). Boston: Edwards Brothers, Inc, 2012.

[42] A. Sueyoshi \& D. M. Hardison. The Role of Gestures and Facial Cues in Second Language Listening Comprehension. Language Learning, 55, 661-699, 2005.

[43] J. Heaton. Teaching culture as a second language: private culture and kinesics. Los Angeles: University of California, 1978. 
[44] A. Pennycook. Actions speak louder than words: Paralanguage, communication, and education. TESOL Quarterly, 19(2), 259-282, 1985.

[45] G. Brindley \& H. Slatyer. Exploring task difficult in ESL listening assessment. Language Testing, 19(4), 369-394, 2002.

[46] M. S. Ghahdarijani. The impact of task complexity on Iranian EFL learners' listening comprehension across anxiety and proficiency levels. Theory and Practice in Language Studies, 2(5), 1057-1068, 2012.

[47] A. Révész \& T. Brunfaut. Text characteristics of task input and difficulty in second language listening comprehension. Studies in Second Language Acquisition, 35(1), 31-65, 2013.

[48] R. Ellis. Individual differences in second language learning.
In A. Davies \& C. Elder (Eds.), The handbook of applied linguistics, 525-551, UK: Blackwell Publishing, 2004.

[49] I. J. B. Liyanage. An exploration of language learning strategies and learner variables of Sri Lankan learners of English as L2 with special reference to their personality types. (Unpublished doctoral dissertation). Griffith University, Australia, 2004.

[50] P. M. Lightbown \& N. Spada. How languages are learned. Oxford: Oxford University Press, 2006.

[51] L. K. Steil, L. L. Barker \& K. W. Watson. Effective listening: Key to your success. Boston, MA: Addison-Wesley, 1983.

[52] M. Purdy \& N. Newman. Listening and gender: Characteristics of good and poor listeners. Paper presented at the International Listening Association Convention, Albuquerque, NM, 1999. 